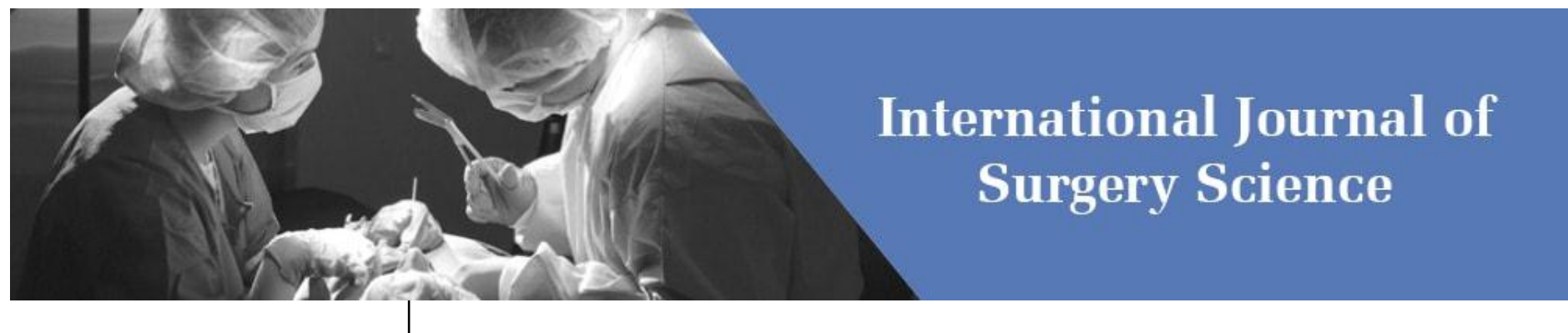

E-ISSN: 2616-3470

P-ISSN: 2616-3462

(C) Surgery Science

www.surgeryscience.com

2022; 6(1): 130-133

Received: 18-10-2021

Accepted: 02-12-2021

Dr. Bhavin Kothari

Associate Professor, Department of Surgery, Gujarat Adani Institute of Medical Science, Bhuj, Gujarat, India

Corresponding Author: Dr. Elizabeth Anna Samuel Post Graduate Student, Department of ENT, Sree Mookambika Institute of Medical Sciences, Kulasekharam, Tamil Nadu, India

\section{Clinical study and surgical management of diabetic foot: An observational study}

\section{Dr. Bhavin Kothari}

DOI: https://doi.org/10.33545/surgery.2022.v6.i1c.831

\section{Abstract}

Background and Aim: The most frequent reason for hospitalization for patients with diabetes is foot complications, which accounts for up to $25 \%$ of all diabetic admissions. The clinical triad most commonly seen in diabetic foot ulcer is peripheral sensory neuropathy, trauma and deformity. Diabetes continues to be one of the most common underlying causes of nontraumatic lower extremity amputations (LEAs). The aim of the study was to study the benefit and outcome of the different treatment modalities for the diabetic foot. Material and Methods: This study was conducted comprising 200 patients with diabetic foot in the department of general surgery at Gujarat Adani Institute of Medical Science, Bhuj, Kutch for 10 months. Data were collected by detailed history, clinical examination, wound or ulcer and were recorded in the predesigned proforma. Wagner's classification, examination findings, blood investigations, renal function test, a swab of the wound, X-ray and treatment provided were collected.

Results: Most of the patients had diabetes duration for about 6-10 years (28\%). Out of 200 SG cases, 88 (44\%) cases presented with ulcers, $40(20 \%)$ cases with cellulitis $32(16 \%)$ of cases abscess, $48(24 \%)$ of cases gangrene and $8(4 \%)$ of cases neuropathic ulcer. The most common site of lesion in the diabetic foot was the dorsum of the foot which was in about 64 patients (32\%). Out of the 200 cases studied 120 patients $(60 \%)$ not had a history of trauma and 80 patients $(40 \%)$ not had a history of trauma.

Conclusion: The commonest presenting lesion was ulcers, followed by gangrene and cellulitis. The commonest site of lesion was the dorsum of the foot followed by forefoot and toes. The most common microorganisms grown from culture taken from the lesion was S. aureus followed by Pseudomonas. Ulceration, infection, gangrene and lower extremity amputation are complications often encountered in patients with DM.

Keywords: Amputation, diabetes, gangrene, ulceration

\section{Introduction}

Diabetes mellitus is a universal syndrome with metabolic, vascular and neuropathic components. The metabolic syndrome is characterized by alteration in carbohydrate, fat and protein metabolism secondary to absent or markedly decreased insulin secretion and/or insulin resistance ${ }^{[1]}$. one of the most dreaded complications seen in diabetes is a foot problem now termed as" Diabetic Foot Syndrome". Presence of foot problem restricts the mobility of the patient, but often requires intensive medical care often associated with prolonged hospital stay and surgical intervention ${ }^{[1]}$. The World Health Organization (WHO) defines diabetic foot as the lower limb of a diabetic patient that has potential risk of pathological consequences, including infection, ulceration, and/or destruction of deep tissues associated with neurologic abnormalities, various degrees of peripheral vascular disease, and/or metabolic complications of diabetes.

Neuropathy appears to be the single-most important factor not only in developing diabetic foot but also in delaying the healing process. Patients having sensory loss appear to have seven times increased risk of developing foot ulcer. Origin of neuropathy remains unclear ${ }^{[2]}$. It may be due to insufficiency of intrinsic blood supply to peripheral nerves, may be autoimmune or microvascular ischemia caused by the accumulates of advanced glycosylated endproducts. ${ }^{[3,4]}$ Peripheral vascular disease is another important risk factor and is mainly due to widespread and often multisegmental atherosclerosis of large vessels of the leg. It is often bilateral and distal involving tibial and peroneal vessels below knee due to unknown reason ${ }^{[5]}$.

Foot disorders are a major source of morbidity and a leading cause of hospitalization for persons with diabetes ${ }^{[6]}$. Eighty-five percent of diabetic major amputations begin with a foot ulcer and the common pathway to amputation involves infection entering the foot and leading to gangrene. 
Four categories of diabetes are recognized. Type 1, formerly insulin-dependent diabetes mellitus (IDDM) is an autoimmune disease affecting the pancreas. Individuals with type 1 diabetes are prone to ketosis and unable to produce endogenous insulin. Type 2, formerly non-insulin-dependent diabetes mellitus (NIDDM), accounts for $90 \%$ to $95 \%$ of cases diagnosed. Type 2 diabetes is characterized by hyperglycemia in the presence of hyperinsulinemia due to peripheral insulin resistance [7]. Gestational as well as genetic defects and endocrinopathies are recognized as other types of diabetes. Diabetes is associated with numerous complications related to microvascular, macrovascular and metabolic etiologies. These include cerebrovascular, cardiovascular and peripheral arterial disease, retinopathy, neuropathy and nephropathy ${ }^{[8]}$.

Diabetes continues to be one of the most common underlying causes of nontraumatic lower extremity amputations (LEAs). The other fifteen percent of major amputations will be due to rest pain, ischemia that has destroyed the foot or an unstable Charcot joint ${ }^{[9]}$. Every 30 seconds, a lower limb or a part of a lower limb is lost somewhere in the world as a consequence of diabetes. Up to $70 \%$ of all lower-limb amputations are performed on people with diabetes. Every year, approximately 4 million people develop a new diabetic foot ulcer. The DM is the fourth to the fifth leading cause of death in developed countries [10]

\section{Material and Methods}

This study was conducted comprising 200 patients with diabetic foot in the department of general surgery at Gujarat Adani Institute of Medical Science, Bhuj, Kutch for 10 months. Data were collected by detailed history, clinical examination, wound or ulcer and were recorded in the pre-designed proforma. Wagner's classification, examination findings, blood investigations, renal function test, a swab of the wound, X-ray and treatment provided were collected. All patients are studied and clinical findings are recorded as per proforma case sheet data analyzed and necessary investigations done as per required and treatment given. Predisposing factors, complications, treatment and sequel are studied, analyzed stand discussed.

Patients with foot infections without DM were excluded. Patients with gangrene foot of etiology other than infection of foot complicated by diabetes were excluded. Patients whose treatment could not be completed due to noncompliance were also excluded. Patients with incidental diagnosis of diabetes on admission were also excluded.

\section{Statistical analysis}

The recorded data was compiled and entered in a spreadsheet computer program (Microsoft Excel 2007) and then exported to data editor page of SPSS version 15 (SPSS Inc., Chicago, Illinois, USA). For all tests, confidence level and level of significance were set at $95 \%$ and $5 \%$ respectively.

\section{Results}

Of 200 cases studied, most of the diabetic patients with foot lesions were in the age group of 61-70 (32\%) followed by 51-60 (24\%) (Table 1). The youngest was 29 years, came with complaints of abscess over the (R) forefoot and the oldest was 78 years admitted for cellulitis of $(\mathrm{R})$ the whole forefoot. 156 (78\%) were male patients and 44 cases females patients. Most of the patients had diabetes duration for about 6-10 years (28\%). Two patients had a history of diabetes for only 4 months and a 78 year old male patient came with a history of diabetes with duration of 24 years. Out of 200 SG cases, 88 (44\%) cases presented with ulcers, $40(20 \%)$ cases with cellulitis $32(16 \%)$ of cases abscess, $48(24 \%)$ of cases gangrene and 8 (4\%) of cases neuropathic ulcer (Table 2). The most common site of lesion in the diabetic foot was the dorsum of the foot which was in about 64 patients (32\%). Whole forefoot comprised about 56 cases (28\%). The least was heel which was about $8(4 \%)$ patients. Out of the 200 cases studied 120 patients $(60 \%)$ not had a history of trauma and 80 patients $(40 \%)$ not had a history of trauma. In the present study $104(52 \%)$ patients presented with neuropathy. Ischemia was seen in 120 patients and there was an infection in 164 patients. The most common microorganism grown on the culture of pus was Staphylococcus aureus in 60 (30\%) patients followed by Pseudomonas 36 (18\%), Streptococcus 28 (14\%), E. coli $20(10 \%)$, Klebsiella $16(8 \%)$ and Proteus $12(6 \%)$ (Table $3)$. In $28(14 \%)$ patients there was no growth seen on culture some cultures yielded more than one type of bacteria.

Out of 200 patients treated $24(12 \%)$ patients were managed conservatively by/slough excision and regular dressing with antibiotics with diabetic control. $56(28 \%)$ patients were treated with wound debridement, $20(10 \%)$ patients treated with SSG, $12(6 \%)$ patients underwent I and D for abscess and $20(10 \%)$ patients underwent $\mathrm{J}$ fasciotomy and 32 (16\%) patients presented with gangrene of toes and phalanges were $M$ treated with disarticulation. 8 (4\%) patients underwent below-knee amputation and $28(14 \%)$ patients were above-knee amputation. In most cases, the limb was salvaged by conservative treatment and minor computations. In this study minimum stay in the hospital was 10 days and the maximum was 100 days. The most common duration of hospital stay was between 21-40 days $(36 \%)$.

Table 1: Age wise Distribution of Study Participants

\begin{tabular}{|c|c|c|}
\hline Age In Years & Number & Percentage (\%) \\
\hline $11-20$ & 0 & 0 \\
\hline $21-30$ & 0 & 0 \\
\hline $31-40$ & 24 & 12 \\
\hline $41-50$ & 24 & 12 \\
\hline $51-60$ & 48 & 24 \\
\hline $61-70$ & 64 & 32 \\
\hline $71-80$ & 40 & 20 \\
\hline Total & 200 & 100 \\
\hline
\end{tabular}

Table 2: Clinical presentations

\begin{tabular}{|c|c|c|}
\hline Clinical presentations & Number & Percentage (\%) \\
\hline Ulcer & 88 & 44 \\
\hline Cellulitis & 40 & 20 \\
\hline Abscess & 16 & 32 \\
\hline Gangrene & 48 & 24 \\
\hline Neuropathic ulcer & 8 & 4 \\
\hline Total & 200 & 100 \\
\hline
\end{tabular}

Table 3: Culture and sensitivity

\begin{tabular}{|c|c|c|}
\hline Organisms & Number & Percentage (\%) \\
\hline Staphlococcus aureus & 60 & 30 \\
\hline Streptococcus & 28 & 14 \\
\hline Pseudomonas & 36 & 18 \\
\hline E. coli & 20 & 10 \\
\hline Klebsiella & 16 & 8 \\
\hline Proteus & 12 & 6 \\
\hline No growth & 28 & 14 \\
\hline
\end{tabular}

\section{Discussion}

In this millennium, the issue of chronic wound management still remains an enigmatic challenge ${ }^{[11]}$. Foot ulceration is a major 
complication of diabetes and consumes a major portion of the resources allocated for the treatment of diabetes [12]. the mortality rate in patients with diabetic foot ulceration is also high and is approximately twice that of patients without ulceration ${ }^{[13]}$. many ulcers are potentially preventable and are therefore of neuropathic or neuroischemic etiology [14, 15]. neuropathy and peripheral vascular disease have been identified as major risk factors for diabetic foot ulceration and amputation. Diabetic foot disease is one of the most feared complications of diabetes mellitus. Ultimately, as an end point, it can lead to complete loss of vascularity and dead and necrotic tissues and thus amputation, which are always a traumatic experience and associated with significant morbidity and mortality, along with immense social, psychological, and financial consequences.

In our present study, the most common cause of diabetic foot was trauma in $70 \%$ and the remaining as complications of their diabetic status ${ }^{[16]}$. It is also observed in our study that $60 \%$ of diabetic foot occurred among those who walked barefoot and $35 \%$ in those wearing only slippers or chappals while only $5 \%$ prevalence was observed in those wearing shoes. This observation revealed that proneness to injuries increased the risk of developing diabetic foot lesions $(\mathrm{p}<0.001)^{[17]}$. In Wagner's grade 2 through, the overall chance of local or major amputation is estimated to be around $60 \%$. In the present study, the patients with diabetic foot presented with abscess $(2 \%)$, cellulitis $(23 \%)$, ulcer $(55 \%)$ and gangrene $(20 \%)$. The ulcer pattern ranged from $94 \%$ in grade $2,20 \%$ in grade $3,36 \%$ in grade 4 and $3 \%$ in grade 5 category ${ }^{[18]}$. Similarly, Porter et al. from Mexico hospital have also reported $23 \%$ of their diabetic cases with grade 2 ulcers and $21 \%$ with grade $3^{[19]}$.

Christian et al. ${ }^{[20]}$ showed diabetic patients with foot ulceration showed an up regulation of circulating levels of a range of acutephase proteins, cytokines, and chemokines and lower levels of the chemokine rantes compared with diabetic patients without a history of foot ulcer. Various screening techniques have been proposed and are currently in use. These include the evaluation of vibration perception threshold (vpt), plantar foot pressure measurements, joint mobility, and 5.07 semmes weinstein monofilament (swf) testing.

Reed et al. have stated that although gram-positive organisms are overwhelming in chronic diabetic ulcers, the polymicrobial nature of bacterial growth should not be ignored in the management planning, especially in developing countries [21]. The pattern of infection as observed in the present study reveals that while $73 \%$ of cases were infected with a single infection of the gram-positive organism, $18 \%$ of cases had polymicrobial infections. Among these E. coli and Proteus were the predominant microorganisms involved ${ }^{[22]}$. Chronic ulcers are frequently co-existing with fungal infections of the foot and it has been said that bacterial infection could be predisposed by a fungal infection ${ }^{[23]}$. Schadewaldt et al. ${ }^{[24]}$ in 1987 from Korea in a study of 13,271 patients with diabetes have shown that $78.4 \%$ have a fungal infection of the feet.

\section{Conclusion}

The commonest presenting lesion was ulcers, followed by gangrene and cellulitis. The commonest site of lesion was the dorsum of the foot followed by forefoot and toes. The most common microorganisms grown from culture taken from the lesion was $\mathrm{S}$. aureus followed by Pseudomonas. Ulceration, infection, gangrene and lower extremity amputation are complications often encountered in patients with DM. These complications frequently result in extensive morbidity, repeated hospitalizations and mortality.

\section{References}

1. Amos A, McCarty D, Zimmet P. The rising global burden of diabetes and its complications: estimates and projections to the year 2010. Diabet Med. 1997;14(5):1-85.

2. Arieff AI, Carroll HJ. Nonketotic hyperosmolar coma with hyperglycemia: clinical features, pathophysiology, renal function, acid-base balance, plasma- cerebrospinal fluid equilibria, and the effects of therapy in 37 cases. Medicine (Baltimore). 1972;51(2):73-94.

3. Armstrong DG, Stacpoole-Shea S, Nguyen H, Harkless LB. Lengthening of the Achilles tendon in diabetic patients who are at high risk for ulceration of the foot. J Bone Joint Surg Am. 1999;81(4):535-8.

4. Gibbons GW, Habershaw. Management of diabetic foot problems, 1984, 176-180.

5. Mc Neely, The independent contributions of diabetic neuropathy and vasculopathy in diabetic foot ulceration. Diabetes care, 1995.

6. Adzick Scott N. Wound healing - biologic and clinical process" Sabiston text book of surgery, 2001.

7. Reiber GE, Lower extremity foot ulcers and amputations in diabetes.

8. Buse JB, Polonsky KS. Diabetic ketoacidosis, hyperglycemic hyperosmolar nonketotic coma and hypoglycemia. In: Hall JBM, Schmidt GA, Woods LDH, eds. Principles of Critical Care Medicine. 2nd ed. New York: McGraw-Hill, 1998: 1183-93.

9. Castano L, Eisenbarth GS. Type-I diabetes. A chronic autoimmune disease of humans, mice, and rats. Annu Rev Immunol. 1990;8:647-79.

10. Diabetes Control and Complications Trial Research Group. The effect of intensive diabetes therapy on the development and progression of neuropathy. Ann Intern Med. 1995;122:561-8.

11. M Madan T K Naveen and M Balachandra. A study of surgical management of diabetic limb complications among rural population. Indian J Surg. Apr 2012;74(2):131-135.

12. American Diabetes Association: Diabetes 1996 Vital Statistics. Alexandria, VA, American Diabetes Association, 1996, 31.

13. Boyko EJ, Ahroni JH, Smith DG, Davignon D. Increased mortality associated with diabetic foot ulcer. Diabet Med. 1996;13:967-972.

14. Thomson FJ, Veves A, Ashe H, Knowles EA, Gem J, Walker MG, Hirst P, Boulton AJM: A team approach to diabetic foot care: the Manchester experience. Foot. 1991;1:75-82.

15. Edmonds ME, Blundell MP, Morris HE, Maelor-Thomas E, Cotton LT, Watkins PJ. Improved survival of the diabetic foot: the role of the specialist foot clinic. Q J Med. 1986;232:763-771.

16. Laguesse E. Structure et development du pancreas d'apres les travaux recents. J Anat (Paris). 1894;30:591-608.

17. Laing $P$. The development and complications of diabetic foot ulcers. Am J Surg. 1998;176:11-9.

18. McNeely MJ, Boyko EJ, Ahroni JH, Stensel VL, Reiber GE, Smith DG, et al. The independent contributions of diabetic neuropathy and vasculopathy in foot ulceration. How great are risks? Diabetes Care. 1995;18(2):216-9.

19. Porter R. The greatest benefit to mankind, a medical history of humanity. 1st ed. New York: WW Norton, 2010, 71.

20. Weigelt C, Rose B, Poschen U, Ziegler D, Friese G, Kempf $\mathrm{K}$, et al. Immune Mediators in Patients with Acute Diabetic Foot Syndrome. Diabetes Care, August. 2009;32(8). 
21. Reed JF. An audit of lower extremity complications in octogenarian patients with diabetes mellitus. Int J Low Extrem Wounds. 2004;3(3):161-4.

22. Reiber GE. Epidemiology of foot ulcers and amputation in the diabetic foot. In: Bowker JH, Pfeifer MA, eds. The diabetic foot. 6th ed. St. Louis, Mo: Mosby Inc, 2001, 1332.

23. Reiber GE, Vileikyte L, Boyko EJ, Aguila MD, Smith DG, Lavery LA, et al. Causal pathways for incident lowerextremity ulcers in patients with diabetes from two settings. Diabetes Care. 1999;22(1):157-62.

24. Schadewaldt $H$. The history of diabetes mellitus. In: Englehardt DV, eds. Diabetes, its medical and cultural history. Berlin: Springer Verlag, 1987, 43-100. 